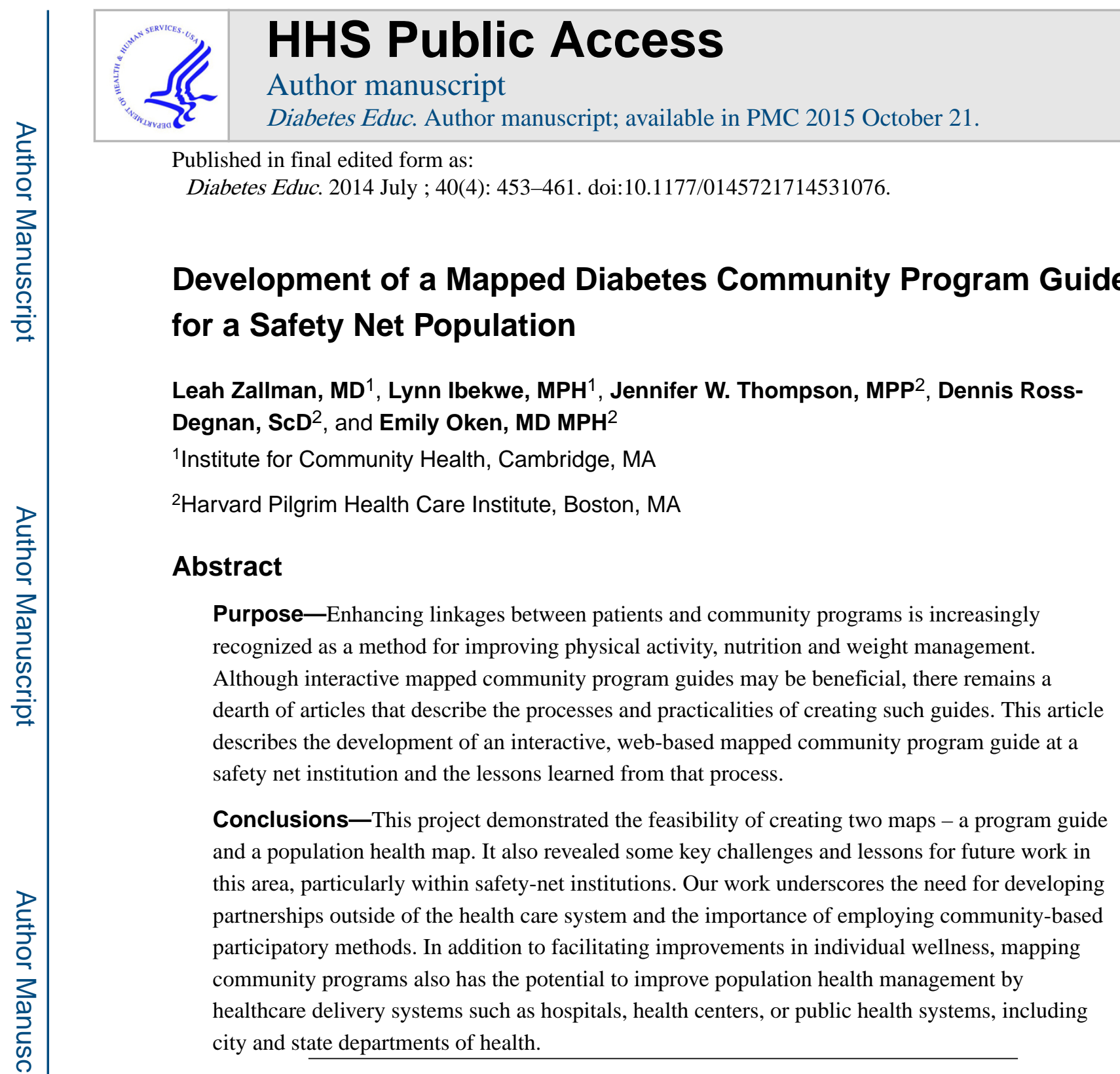

Optimal physical activity, nutrition, and weight management behaviors can improve health and well-being, while reducing morbidity, disability, and death ${ }^{1-4}$. The health care setting provides a natural forum in which to promote healthful behaviors, especially for individuals seeking care for lifestyle-related health conditions such as hypertension or type 2 diabetes mellitus. Evidence suggests that counseling by healthcare providers results in positive health behaviors, such as more weight loss attempts and increased intentions to exercise or eat better. ${ }^{5-7}$ Lifestyle modification interventions in clinical settings aimed to prevent diabetes have demonstrated significant clinical benefit. ${ }^{8-10}$ However, healthcare providers face significant barriers in incorporating lifestyle counseling into their routine practices, including a lack of time, appropriate training, and practice-based resources, as well as poor reimbursement for counseling services. ${ }^{11,12}$ Consequently, the full potential of the healthcare system to promote healthful behaviors has not yet been realized.

Address correspondence and reprint requests to: Emily Oken MD MPH Harvard Pilgrim Health Care Institute HMS Department of Population Medicine and the Office of Sponsored Programs 133 Brookline Avenue $6{ }^{\text {th }}$ Floor Boston, MA 02215 Telephone: (617) 509-9987 Fax: (617) 859-8112 y_oken@ harvardpilgrim.org. 
Easily accessible links to existing community programs may be a mechanism for overcoming some of the barriers to clinic-based lifestyle counseling. The benefits of encouraging patients to engage with community organizations to enhance behavior change are increasingly recognized. ${ }^{13}$ For example, in a cross-sectional study of 54 primary care practices, those that had both tools to identify high risk patients and linking strategies for physical activity counseling were $80 \%$ more likely to have patients who reported exercising regularly compared to practices that lacked both. ${ }^{14}$ However, information about existing community programs is not readily available in most clinical settings.

Some complex multi-component interventions designed to improve physical activity have incorporated community program guides. ${ }^{15}$ In these research settings, incorporating community program guides resulted in enhanced provider counseling about exercise, referrals to community programs, increased patient physical activity levels. Also, providers reported positive attitudes about referring patients to community programs for physical activity. ${ }^{16}$

Thus far, most health program guides have displayed community resource information as lists of programs ${ }^{17,18}$. Given the widespread accessibility of the Internet, web-based health program guides would offer additional advantages, such as the ability to search for keywords (e.g., 'basketball'), to filter by feature (e.g., ages served) ${ }^{19}$, or to display programs on a map in order to rapidly identify programs in close proximity to key points of interest (e.g., home, school, or workplace). These interactive mapping techniques have recently become highly valued health communication methods for use in public health intervention planning and disease surveillance. ${ }^{20,21}$ The typical audiences for interactive mapping to date have been public health planners, policymakers, and health delivery systems rather than patients or communities.

While interactive, web-based, mapped community program guides may be beneficial, we are aware of no articles that describe the processes and practicalities of creating such guides. This article describes the development of an interactive, web-based mapped community program guide for a safety-net institution, and the lessons learned from that process.

\section{Development Process}

\section{Setting and context}

CHA is an urban, integrated safety net health care system that includes two hospitals and 16 community health centers serving 100,000 patients in the greater Boston, MA area. The health care system spans five adjacent towns and has a robust electronic health record (EHR) system that includes a patient portal. As a safety net health care system, CHA cares for a low-income, vulnerable and historically underserved population with a high proportion of patients who are either uninsured or on government-sponsored insurance. Its population is racially and ethnically diverse, comprised of $15 \%$ Black non-Hispanic, $44 \%$ White nonHispanic, 19\% Hispanic, 5\% Asian, and 17\% Other individuals. About one-third of CHA's patients speak a language other than English at home, with Portuguese (19\%) and Spanish (9\%) being the largest subgroups. CHA patients are insured by Medicaid or other 
government sponsored insurance (43\%), Medicare (29\%), private insurance (20\%), or are uninsured $(9 \%)$.

\section{Collaborating organizations and project team}

A community-based participatory research and evaluation organization (Institute for Community Health, or ICH) that is closely aligned with a safety net health care system (Cambridge Health Alliance, CHA) partnered with an academic research department (Department of Population Medicine at Harvard Medical School, HMS) to develop a family diabetes and obesity prevention community program guide. The project team aimed to develop a comprehensive list of physical activity, nutrition, and weight management community programs, which would be plotted on an interactive, web-based map for the five towns in CHA's catchment area. The development of this program guide was envisioned as formative work towards a larger effort to improve diabetes prevention for CHA patients and individuals living in the surrounding communities.

The project team consisted of faculty and staff from ICH and HMS, including primary care physicians (one of whom practices at CHA), academic health services researchers, project managers working on related diabetes prevention activities, a research associate, and three public health students. The project team held bi-weekly meetings by phone or in person to discuss project goals, progress, and products.

\section{Overview of development process}

A community based participatory research (CBPR) ${ }^{22}$ approach was used to develop the program guide. CBPR has been successfully used to develop resource guides relevant to target communities such as minorities. ${ }^{23}$ Though the current work was not research, community members were invited to join in a cooperative, respectful and engaging process to guide the development of the program guide. Community member input—obtained through informant interviews and focus groups-was sought on all stages of development from conception to dissemination. We combined this input with results from internet searches to develop a comprehensive guide that would be useful to end-users.

\section{Identifying community resources}

To generate the information in the program guide database, the team adapted a methodology used in previous efforts to identify community programs for a weight loss intervention targeting children. ${ }^{24}$ The team searched an existing online compendium of physical activity, nutrition and weight management programs for communities in the CHA catchment area and conducted an internet search to identify new programs and to confirm details for programs listed in the compendium. Test searches on several different online search engines led to the selection of the one (Google.com) that produced the most relevant information most efficiently. After conducting several test searches, it was decided that the first five pages of results ; this threshold struck the optimum balance between search time and the comprehensiveness of the program list.

The team developed an initial set of 44 physical activity terms, 10 nutrition terms, and 9 weight management terms to search; because these terms would capture all diabetes 
prevention programs, the team did not include a specific term for diabetes prevention.. The team used search terms combined with each community name in the catchment area for each program area in the guide. Examples include "basketball" and "community pools" to search for physical activity programs; "farmers' markets" and "healthy eating" to search for nutrition programs; and "childhood obesity programs" and "weight loss programs" to search for weight management programs. We also searched the websites of hospitals, health centers, community centers, recreation centers, fitness centers, etc. to find venues with a broad range of activities and programs. In addition, key informants suggested additional search terms and provided names of specific nutrition and weight management community programs. The final list of search terms is available in the appendix.

The accuracy of the program data was verified by calling a random sample of the identified programs/activities to validate four pieces of information (phone number, physical address, ages served, and program description). If a program was not reached on the first day, one further call was attempted.

The team partnered with a local university geographic analysis center to create the online, searchable community resource map. This center provided assistance with geocoding (i.e., conversion of street addresses for the programs into geographical coordinates) and mapping, as well as expertise on customizing the mapping platform to improve user-friendliness and aesthetics. The center provided guidance concerning choice of web interface; ultimately we chose WorldMap@ because it has built-in system updating and would therefore require no ongoing maintenance. Additionally, WorldMap has a mobile version so that users could easily navigate the database on mobile devices.

\section{Key informant interviews}

In initial meetings, the project team determined the types of formative information needed to refine the tool and adapt it to the clinical context. This information was to be collected from key informants within CHA and community organizations. The team identified the following domains to discuss with key informants: (1) suggestions for making the program guide useful to the target population, including the types of information the guide should contain; (2) suggestions and potential challenges for integrating the program guide into clinical care; and (3) suggestions for naming and promoting the community program guide.

Based on her knowledge as a CHA primary care provider, one team member (LZ) identified key informants having a variety of roles within and outside of the organization. The team then conducted one-on-one and group interviews with two diabetes educators, an endocrinologist, a primary care physician with a particular interest in weight management, outpatient nutritionists, representatives of a local city public health department, community affairs department members, two community health workers who work with medically and socially complex patients, the CHA Patient \& Family Advisory Council, and CHA patients including a group of patients who were ICH employees. 


\section{Findings}

\section{Program guide development}

Two maps were created: the program guide (Figure 1) and a population health management map (Figure 2). 436 programs were identified (physical activity $=295$, nutrition $=114$, weight management $=5$, nutrition and physical activity $=17$, nutrition and weight management $=5$ ). The team called 17 programs to verify a total of 68 pieces of information. Of those pieces of information, $42.6 \%$ were accurate, $8.8 \%$ were inaccurate, and $48.5 \%$ were unverified because the team was not able to reach the program after two attempts.

The team also created a population health management map, intended to identify where the populations with high disease burden (i.e., diabetes) live in relation to the location of the community programs. This map overlays the distribution of resources with a map demonstrating the density of CHA patients with diabetes. To develop the population health management map, the CHA IT and population health management teams identified patients who had at least one visit in 2012 coded as ICD-9 250.XX. The team then created a map illustrating the number of patients with diabetes living in each census block in the CHA catchment area. The available community programs were then overlaid on this map. Review of a map for one such community (Figure 1) suggests that weight and exercise programs are concentrated in areas where few CHA diabetic patients reside. Population health teams and public health departments could use maps such as these to advocate for more rational program distribution with city planners or public health regulators, or the programs themselves could use it to identify opportunities to reach underserved target populations.

\section{Key informant advice about adapting the program guide: findings from focus group and interviews}

Enhancing usefulness-Both patients and clinicians felt that the mapped program guide could be very useful. They also identified a number of specific features that would make the program guide more useful, including: (1) having a printable version that could be given to patients during the clinic visit, which would help to address computer illiteracy and inaccessibility for some patients; (2) including introductory information on the purpose of the program guide; (3) including additional program types, such as food pantries, Community Supported Agriculture programs, (4) incorporating the program guide into the EHR so that it would be available during the clinical encounter and through the patient portal; (5) creating a mobile phone application to accommodate patients who lacked computer access but had smart phones; (6) linking to body mass index or calorie tracking programs, particularly ones that employed social media connections; (7) translating the program guide into languages other than English; and (8) arranging discounts for programs accessed through the guide.

Public health department informants, who had extensive experience creating community program guides, suggested that the team prototype and pilot the guide with potential users. We therefore developed a pilot prototype of the community program guide and conducted a focus group and one-on-one interviews with 13 patients and community members to obtain feedback regarding modification and planned use of the tool. Pilot respondents felt that the 
prototype Community Wellness Map was useful and easy to navigate. They provided suggestions to clarify language and improve the user interface. Respondents appreciated the symbols for the various resources, suggested removing extraneous links, and requested hyperlinks to program websites.

Integrating the community program guide into clinical care-Both providers and patients indicated that the program guide would be more useful if it was first introduced to a patient by a health provider during a clinic encounter. Patients felt that this process would highlight the importance of physical activity, nutrition, and weight management to their health. Clinicians felt that integration into the clinical encounter would: (1) allow them to take into account patients' physical limitations; (2) support their counseling by incorporating advice about local programs; and (3) link the program guide to patient engagement efforts such as goal-setting and disease tracking. Non-clinical informants (including those from the public health department and CHA's community affairs department) felt that the program guide should also be made available to individuals who are not CHA patients.

Informants had differing views about which clinician should introduce the program guide to a patient. Some thought that the primary care provider would be the best person to make the initial introduction, while others believed that medical assistants, nurses, community health workers, or nutritionists should do so, perhaps after an initial recommendation by the primary care provider. Respondents mentioned issues of provider time availability, degree of patient comfort with different providers, and which providers were most passionate about supporting patients with life style improvements. In light of the issues raised, the team determined that the appropriate clinician might well differ by patient or by clinical site.

Although informants were enthusiastic about the program guide, they highlighted a number of challenges that could affect its usefulness and integration into care. Informants were concerned about time constraints during the clinical encounter, patients' computer illiteracy or language barriers, lack of information on the quality and cost of programs, buy-in by clinic staff and patients, ensuring appropriate training for providers and patients to use the program guide effectively, maintaining up-to-date information, and social barriers to accessing available programs.

Informants suggested a number of solutions to minimize potential challenges. These included using videos to introduce patients to the program guide and making the guide available via mechanisms that patients already use to obtain health information (i.e., television, waiting room fliers, social media). To best utilize the program guide within the EHR, informants suggested a pop-up box or an ordering set, possibly triggered by a high body mass index or diabetes diagnosis, which might include an automatic link to the program guide. They also suggested mechanisms for increasing provider buy-in: (1) introducing the program guide via existing hospital systems such as the Employee Wellness Committee, which had previously run successful weight management efforts among employees, (2) tying program guide use with an incentive, and (3) advertising clinic-specific usage rates in order to encourage competition between clinics. 
Naming and promoting the community program guide-Respondents made a number of suggestions about the name of the program guide and how it should be promoted to engage target users. They suggested choosing a name that emphasized wellness and that clearly grounded the tool in the community in order to maximize perceptions of inclusiveness. The name for the community program guide that the team selected through this process is the Community Wellness Map.

Based on feedback from key informants, the team determined that they needed assistance with making the Community Wellness Map accessible to populations with low health literacy and low computer literacy. The team partnered with a health communications organization that works with researchers, clinicians, and practitioners to develop creative communication strategies to promote evidence-based practice. The health communications organization assisted in various aspects of creating the final Community Wellness Map including graphic design, writing and editing program descriptions, editing the introductory information, and internet search optimization.

\section{Discussion and lessons learned}

The process of conceptualizing and developing the web-based Community Wellness Map revealed some key lessons for future work in this area, particularly within safety-net institutions. While patients, clinicians, and individuals working in community affairs and public health departments were enthusiastic about mapped community program guides and felt that this innovation would benefit community members, they identified several important challenges, including low health literacy, low computer literacy and access, and language needs. Creating a web-based mapped community program guide and addressing these challenges required capacity and expertise in several domains (Table 1). In the health care system in which this work was conducted, as in many others, this expertise was not available within one institution and therefore necessitated several external partnerships.

The work also underscored the importance of employing community-based participatory methods; the resulting product was informed and enriched by key informant interviews and feedback obtained from potential users during prototyping. In addition, the process highlighted the potential of community mapping to serve a dual function: to improve clinical care by providing locally relevant data for patients and clinicians, and at the same time to enhance institutional understanding of the community context in which patients live. Finally, this work highlighted the challenge of keeping community program guides up-to-date. The team explored several mechanisms - including asking users, programs, and people employed in the healthcare system - to keep the program guide updated, but has not yet identified a practical solution.

The team identified several areas for future work. These include working with the health system to incorporate the Community Wellness Map into routine clinical care and obtaining feedback once the guide is being used. Additionally, the team would like to explore community use of the program guide outside of the context of clinical care to understand how it could be modified or adapted to support wellness program uptake. Finally, the team 
envisions incorporating the Community Wellness Map into a multi-faceted communitybased intervention to reduce diabetes risk factors.

\title{
Implications
}

In addition to facilitating improvements in individual wellness, mapping community programs also has the potential to improve population health management by healthcare delivery systems such as hospitals, health centers, or public health systems, including city and state departments of health. The Patient Protection and Affordable Care Act (ACA) encourages the formation of accountable care organizations, with a central goal of improving population health management. As ACOs assume financial risk for the care of their covered populations, one strategy to reduce costs and improve health is to align with community programs that serve those populations. The ACA also includes provisions for increasing the use of electronic health records (EHRs), which allow programs and health delivery systems to identify both areas of high disease prevalence and areas lacking preventive and promotive programs. As this work suggests, these areas may overlap in some communities, supporting greater advocacy to distribute community health programs more equitably.

\section{Acknowledgements}

Drs. Oken and Ross-Degnan are supported in part by the Health Delivery Systems Center for Diabetes Translational Research (HDS-CDTR) [NIDDK grant 1P30-DK092924].

The team would like to thank Elsie Taveras for her early guidance in the conception of this project and Chrissy Horan for her assistance in guiding the development of this program guide. The team would like to thank Kelly O'Connor and Michelle Weiss for their assistance developing the population health map. Finally, the team would like to thank the informants for their suggestions for improving the program guide.

\section{Appendix 1: Community Programs Search Terms List}

\author{
Physical activity (" " in city, state) \\ - Basketball \\ - Dance \\ - $\quad[$ Sports] League \\ - $\quad[$ Sports] Team \\ - $\quad$ Swimming \\ - Football \\ - $\quad$ Fitness centers/clubs \\ - $\quad$ Gym \\ - $\quad$ Recreation center \\ - $\quad$ Baseball \\ - Softball
}




\begin{tabular}{|c|c|}
\hline • & Volleyball \\
\hline - & Community centers \\
\hline • & Exercise \\
\hline • & Physical activity \\
\hline • & Track and field \\
\hline • & Running \\
\hline • & Cross country \\
\hline • & Sports \\
\hline - & Organized physical activity[sports] \\
\hline • & Active living \\
\hline - & Sports activities \\
\hline • & Sports camps \\
\hline - & Sports programs \\
\hline • & Aerobics \\
\hline • & Cheerleading \\
\hline - & Soccer \\
\hline • & Tennis \\
\hline • & Martial arts \\
\hline - & Skating \\
\hline • & Hockey \\
\hline • & Gymnastics \\
\hline • & Yoga and meditation \\
\hline - & Outdoor adventures and scouting \\
\hline • & Pathways \\
\hline • & Summer recreational programs \\
\hline - & After school recreational program \\
\hline • & Aquatic centers \\
\hline - & Pilates \\
\hline - & Walking/biking trails \\
\hline - & Sports facilities \\
\hline - & School tracks, playgrounds, parks \\
\hline - & Community pools \\
\hline
\end{tabular}

Diabetes Educ. Author manuscript; available in PMC 2015 October 21. 
- Hiking

\section{$\underline{\text { Nutrition (" " in city, state) }}$}

- $\quad$ Farmers markets

- $\quad$ YMCA/YWCA/Health centers/Hospitals + nutrition programs

- $\quad$ Healthy eating

- $\quad$ Healthy food and nutrition programs [resources]

- $\quad$ Community Gardens

- $\quad$ Food Pantry [bank]

- $\quad$ Community Supported Agriculture

\section{Weight Management (“" in city, state)}

- $\quad$ Pediatric/adult/family + weight management programs

- $\quad$ Adult/childhood + obesity programs

- $\quad$ Pediatric + weight loss programs

\section{Base Map includes:}

- $\quad$ Parks and Recreation

- $\quad$ Playgrounds

- $\quad$ Bike paths

- $\quad$ Walking Paths

- $\quad$ Bus/T lines

\section{References}

1. U.S. Department of Health and Human Services, U.S. Department of Agriculture. Dietary Guidelines for Americans, 2010. U.S. Department of Health and Human Services; Washington, DC: 2008.

2. U.S. Department of Health and Human Services. [July, 2013] Healthy People 2020.. Topics \& Objectives: Nutrition and Weight Status. 2020. http://www.healthypeople.gov/2020/ topicsobjectives2020/overview.aspx?topicid=29.

3. U.S. Department of Health and Human Services. [July, 2013] Healthy People 2020.. Topics \& Objectives: Physical Activity. 2020. http://www.healthypeople.gov/2020/topicsobjectives2020/ overview.aspx?topicid=33.

4. U.S. Department of Health and Human Services, Office of Disease Prevention and Health Promotion. Physical Activity Guidelines for Americans. U.S. Department of Health and Human Services; Washington, DC: 2008. 2008

5. Huang J, Yu H, Marin E, Brock S, Carden D, Davis T. Physicians' weight loss counseling in two public hospital primary care clinics. Acad Med. 2004; 79(2):156-161. [PubMed: 14744717]

6. Jay M, Gillespie C, Schlair S, Sherman S, Kalet A. Physicians' use of the 5As in counseling obese patients: is the quality of counseling associated with patients' motivation and intention to lose weight? BMC Health Serv Res. 2010; 10:159. [PubMed: 20534160] 
7. Kant AK, Miner P. Physician advice about being overweight: association with self-reported weight loss, dietary, and physical activity behaviors of US adolescents in the National Health and Nutrition Examination Survey, 1999-2002. Pediatrics. 2007; 119(1):e142-147. [PubMed: 17200241]

8. Knowler WC, Barrett-Connor E, Fowler SE, et al. Reduction in the incidence of type 2 diabetes with lifestyle intervention or metformin. N Engl J Med. Feb 7; 2002 346(6):393-403. [PubMed: 11832527]

9. Seidel MC, Powell RO, Zgibor JC, Siminerio LM, Piatt GA. Translating the Diabetes Prevention Program into an urban medically underserved community: a nonrandomized prospective intervention study. Diabetes Care. Apr; 2008 31(4):684-689. [PubMed: 18252904]

10. Tuomilehto J, Lindstrom J, Eriksson JG, et al. Prevention of type 2 diabetes mellitus by changes in lifestyle among subjects with impaired glucose tolerance. N Engl J Med. May 3; 2001 344(18): 1343-1350. [PubMed: 11333990]

11. Etz RS, Cohen DJ, Woolf SH, et al. Bridging Primary Care Practices and Communities to Promote Healthy Behaviors. Am J Prev Med. 2008; 35(5 Suppl):S390-S397. [PubMed: 18929986]

12. Stange KC, Woolf SH, Gjeltema K. One Minute for Prevention: The Power of Leveraging to Fulfill the Promise of Health Behavior Counseling. Am J Prev Med. 2002; 22(4):320-323. [PubMed: 11988386]

13. Woolf, S.; Krist, A.; Rothemich, S. Joining hands: partnerships between physicians and the community in the delivery of preventive care. Center for American Progress; Washington DC: 2006.

14. Balasubramanian B, Cohen D, Clark E, et al. Practice-level approaches for behavioral counseling and patient health behaviors. Am J Prev Med. 2008; 35(5 Suppl):S407-S413. [PubMed: 18929988]

15. Emmons K, Stoddard A, Gutheil C, Suarez E, Lobb R, Fletcher R. Cancer prevention for working class, multi-ethnic populations through health centers: the healthy directions study. Cancer Causes Control. 2003; 14(8):727-737. [PubMed: 14674737]

16. Ackermann R, Deyo R, LoGerfo J. Prompting primary providers to increase community exercise referrals for older adults: a randomized trial. J Am Geriatr Soc. 2005; 53(2):283-289. [PubMed: 15673353]

17. Bayerl CT, Bettencourt M, Lamond C, Spolidoro M, Uy L, Lovesky M. Resource Guide for Pediatric Overweight Treatment Services in Massachusetts: Massachusetts Department of Public Health, Wellness Unit. 2011

18. Cambridge Public Health Department. A Guide to Health, Fitness and Fun for Cambridge Kids 2013. Massachusetts Department of Public Health, Mass in Motion; 2013. Cambridge in Motion..

19. [July, 2013] City of Cambridge MA, City of Somerville MA, Cambridge Health Alliance, The Agenda for Children, The Somerville Community Health Foundation. Cambridge Somerville Resource Guide. http://cambridgesomervilleresourceguide.org/index.aspx.

20. Moore DA, Carpenter TE. Spatial analytical methods and geographic information systems: use in health research and epidemiology. Epidemiol Rev. 1999; 21(2):143-161. [PubMed: 10682254]

21. Parrott R, Hopfer S, Ghetian C, Lengerich E. Mapping as a visual health communication tool: promises and dilemmas. Health Commun. 2007; 22(1):13-24. [PubMed: 17617010]

22. Minkler M, Wallerstein N. Community-Based Participatory Research for Health: Jossey-Bass. 2002

23. Bopp, M.; Fallon, EA.; Bolton, DJ.; Kahl, D. Ethn Dis. Vol. 22. Spring; Engaging community partners to develop a culturally relevant resource guide for physical activity and nutrition.; $\mathrm{p}$. 231-238.

24. Taveras EM, Marshall R, Horan CM, et al. Rationale and design of the STAR randomized controlled trial to accelerate adoption of childhood obesity comparative effectiveness research. Contemp Clin Trials. Jan; 2013 34(1):101-108. [PubMed: 23099100] 


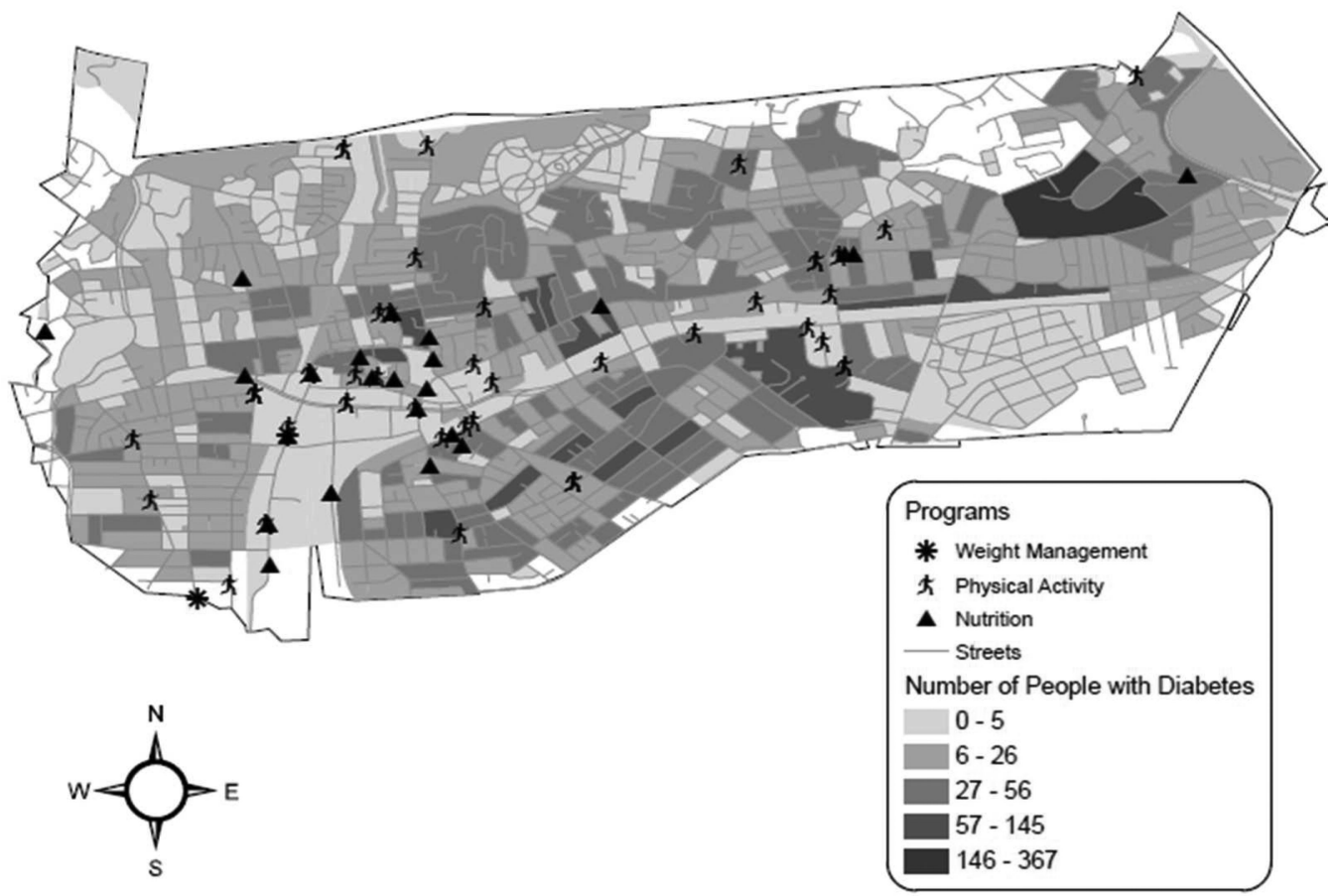

Figure 1.

Sample population health map: Community programs and diabetic patients in one community 


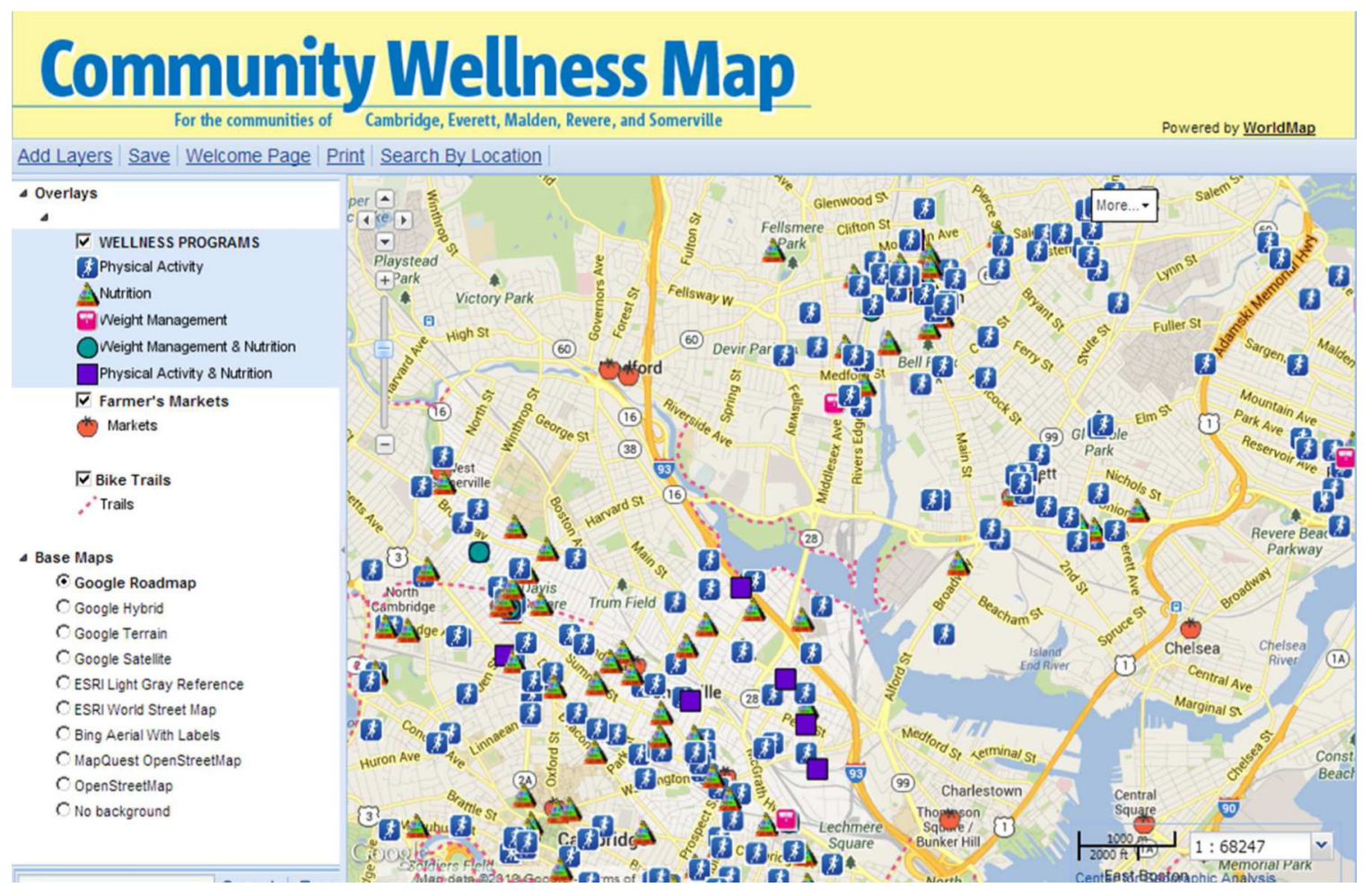

Figure 2.

Community Wellness Map Screenshot 


\section{Table 1}

Resources needed and key lessons learned by aim

\begin{tabular}{|c|c|c|}
\hline Aim & Institutional Resource Capacity Needed & Key Lessons Learned \\
\hline Clinical Care Improvement & $\begin{array}{c}\text { - Understanding of clinical context } \\
\text { - Access to key informants (clinicians, patients, } \\
\text { department of health, community affairs) } \\
\text { - Health literacy and graphic design } \\
\text { - Geocoding and programming to modify map } \\
\text { interface } \\
\text { - Significant time and resources needed to complete } \\
\text { searches and verify information }\end{array}$ & $\begin{array}{l}\text { - Significant enthusiasm and need for mapped } \\
\text { community program guide } \\
\text { - Challenges to development (literacy, web access) } \\
\text { and integration (clinical flow, buy-in) } \\
\text { - Requires significant resource capacity to create; } \\
\text { several partnerships needed }\end{array}$ \\
\hline Population Health Management & $\begin{array}{l}\text { - Analyst to identify patients } \\
\text { - Analyst who can geocode patient data }\end{array}$ & $\begin{array}{l}\text { - Allows identification of under-resourced areas } \\
\text { relative to disease burden }\end{array}$ \\
\hline
\end{tabular}

